\title{
Physical and mental recovery after conventional aortic valve surgery
}

\author{
Johannes Petersen, MD, ${ }^{\mathrm{a}, \mathrm{b}}$ Eik Vettorazzi, MSc, ${ }^{\mathrm{c}}$ Lena Winter, MD,${ }^{\mathrm{b}}$ Wolfram Schmied, MS, \\ Ingrid Kindermann, $\mathrm{MD},{ }^{\mathrm{e}}$ and Hans-Joachim Schäfers, $\mathrm{MD}^{\mathrm{b}}$
}

\section{ABSTRACT}

Objective: Physical and mental recovery are important factors to consider in the treatment of aortic valve disease, and the process of recovery is not well known. We investigated the course of physical and mental recovery directly after conventional aortic valve surgery.

Methods: In a longitudinal study, 60 patients undergoing elective aortic valve surgery were studied preoperatively and at intervals of 4 weeks after aortic valve surgery. The last measurement was taken 6 months postoperatively. Measurements included the 6-minute walk test and $\mathrm{N}$-terminal pro-B-type natriuretic peptide. Mental recovery was assessed by the Short Form Health Survey and the Hospital Anxiety and Depression Scale. All parameters were compared with published healthy norms.

Results: All parameters except for the anxiety score showed a significant decline after the first postoperative measurement at 1 week after aortic valve surgery. The baseline level was restored at 1 to 3 weeks (anxiety, depression, mental quality of life, Borg scale), 4 to 6 weeks (6-minute walk test, physical quality of life), and 9 weeks (N-terminal pro-B-type natriuretic peptide) after the first postoperative week. Significantly better values than preoperatively for the first time were reached at 2 to 3 weeks (anxiety, depression, mental quality of life), 5 weeks (6-minute walk test), 8 weeks (physical quality of life), and 12 weeks (N-terminal pro-B-type natriuretic peptide) after the first postoperative week. At 3 months postoperatively, significant improvements $(P<.001)$ were seen in walk distance $(+212 \mathrm{~m})$, dyspnea $(-1.11)$, physical $(+12.38)$ and mental quality of life $(+7.71)$, anxiety $(-3.74)$, and depression $(-3.62)$ compared with the first week postoperatively. At 6 months postoperatively, all parameters were significantly improved compared with preoperative data and, except for the N-terminal pro-B-type natriuretic peptide value, significantly better or equal compared with published healthy norms.

Conclusions: After conventional aortic valve surgery, the most pronounced recovery was seen in the first 6 weeks postoperatively. Physical quality of life and N-terminal pro-B-type natriuretic peptide required a prolonged time for a complete recovery. (J Thorac Cardiovasc Surg 2016;152:1549-56)

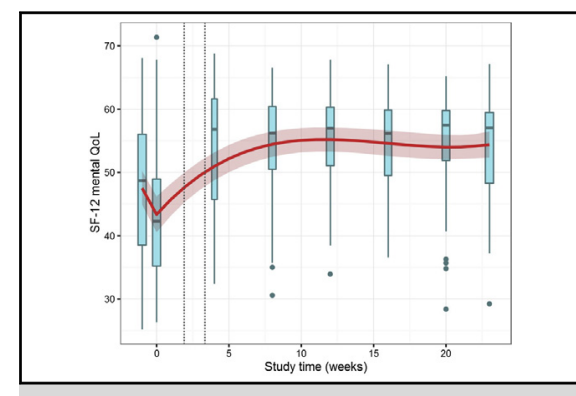

Changes in SF-12 mental QoL over time.

Central Message

After conventional AVS, the most pronounced recovery was seen in the first 6 weeks postoperatively.

\section{Perspective}

Recovery after conventional aortic valve replacement shows rapid improvement in the first 2 months. This provides a baseline for comparison with the results of catheter-based aortic valve procedures

See Editorial Commentary page 1557.

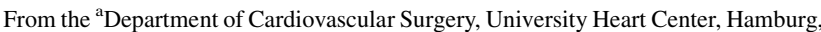
Germany; Departments of ${ }^{\mathrm{b}}$ Thoracic and Cardiovascular Surgery and ${ }^{\mathrm{e}} \mathrm{Cardiology}$, Angiology and Intensive Care Medicine, Saarland University Medical Center, Homburg/Saar; ${ }^{c}$ Department of Medical Biometry and Epidemiology, University Medical Center Hamburg-Eppendorf, Hamburg; and ${ }^{\mathrm{d}}$ Clinic for Psychosomatic Medicine, Mediclin Bliestal Clinics, Blieskastel, Germany.

J.P. and E.V. contributed equally.

Received for publication Dec 15, 2015; revisions received June 29, 2016; accepted for publication July 13, 2016; available ahead of print Oct 14, 2016.

Address for reprints: Hans-Joachim Schäfers, MD, Department of Thoracic and Cardiovascular Surgery, Saarland University Medical Center, Homburg/Saar, Germany (E-mail: h-j.schaefers@uks.eu).

$0022-5223 / \$ 36.00$

Copyright (c) 2016 by The American Association for Thoracic Surgery

http://dx.doi.org/10.1016/j.jtcvs.2016.07.072
}

Valvular heart disease is one of the major causes of heart diseases in industrialized countries, with aortic valve disease being the most common. ${ }^{1}$ Aortic valve replacement has been the standard of care for aortic valve disease

Scanning this QR code will take you to a supplemental tables and video for the article. 


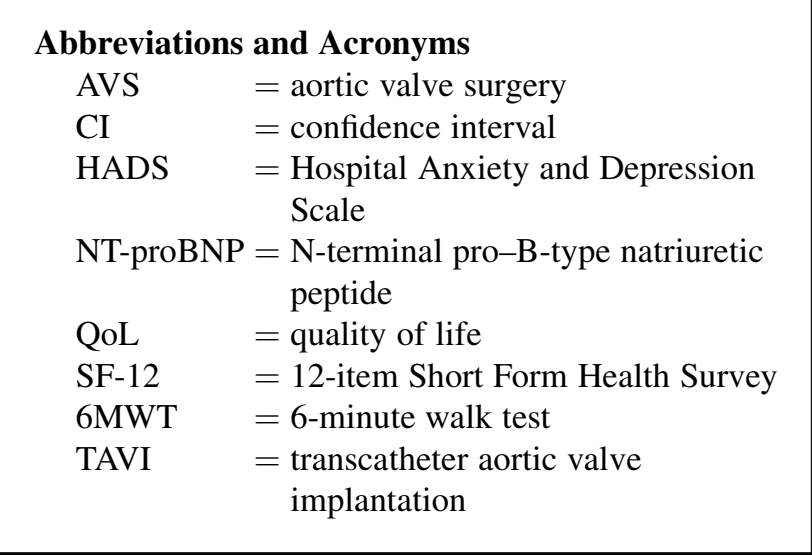

because it improves symptoms and survival ${ }^{2}$ and is associated with good long-term results. ${ }^{3}$ Aortic valve repair (Video 1) has become a reproducible operation for aortic valve regurgitation with decreased valve-related complications. ${ }^{4}$ Most studies have analyzed hospital mortality, valverelated complications, and long-term survival as markers for successful treatment. ${ }^{2-4}$ In recent years, patients and physicians have turned their attention toward other aspects, such as quality of life (QoL) and the process of recovery after surgery. Few data exist regarding the course of physical and mental recovery in the first postoperative months after aortic valve surgery (AVS).

Different functional parameters can be used in the assessment of recovery after AVS. The 6-minute walk test (6MWT) is an accepted tool in the assessment of cardiopulmonary functional capacity. ${ }^{5}$ In AVS, the 6MWT has been used preoperatively to predict mortality ${ }^{6}$ and postoperatively to assess the recovery in rehabilitation facilities. $^{7,8}$ However, no longitudinal study has evaluated the 6MWT before and after conventional AVS. $\mathrm{N}$-terminal pro-B-type natriuretic peptide (NT-proBNP) has been established as a sensitive biomarker that reflects pathologic ventricular overload in patients with congestive heart failure. ${ }^{9}$ Different studies evaluated the weekly change of NT-proBNP from baseline to 4 weeks postoperatively ${ }^{10}$ or the reduction from baseline to 6 or 12 months after AVS. ${ }^{11,12}$ Physical and mental QoL have been assessed most frequently by the 12-item Short Form Health Survey (SF-12) ${ }^{13}$ Improvement in physical and mental QoL has been reported from baseline to 18 months ${ }^{14}$ after AVS. Anxiety and depression have been evaluated most often by the Hospital Anxiety and Depression Scale (HADS). ${ }^{15}$ Although high anxiety and depression scores have been recognized as a predictor for postoperative mortality after cardiac surgeries,${ }^{16,17}$ no longitudinal study has described the course of anxiety and depression after conventional AVS.

To the best of our knowledge, no investigation has been published that evaluated the course of the physical and mental recovery process in a monthly pattern, especially

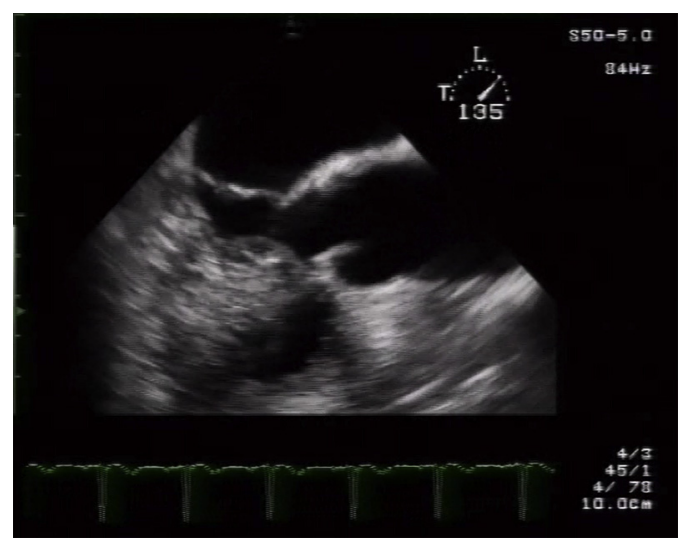

VIDEO 1. Aortic valve repair of a tricuspid aortic valve (length: 04:56 minutes). Video available at: http://www.jtcvsonline.org/article/S00225223(16)31031-5/addons.

regarding 6MWT, anxiety, and depression after AVS. Therefore, we investigated the postoperative course of patients' clinical dyspnea with the modified Borg scale, functional capacity with the 6MWT, heart failure with the NT-proBNP, QoL with the SF-12, and anxiety with the HADS in a longitudinal fashion. The aim of this study was to determine the time frame of a completed recovery after AVS and to compare it with a healthy population.

\section{MATERIAL AND METHODS Patients}

In this prospective clinical study, we consecutively included 60 patients who underwent elective conventional AVS for aortic valve disease from 2010 to 2012. A restriction to participation was to complete 7 of 8 measurements. The baseline characteristics are outlined in Table 1. The predominant aortic valve disease was aortic stenosis $(66.7 \%)$ or aortic regurgitation $(33.3 \%)$. Of the 60 participants of this study, 19 underwent aortic valve repair $(31.7 \%), 37$ underwent valve replacement with a bioprosthesis $(61.7 \%), 3$ underwent aortic valve replacement with a mechanical prosthesis $(5 \%)$, and 1 underwent aortic valve replacement with a pulmonary autograft $(1.7 \%)$. Overall, 34 patients $(56.7 \%)$ had an isolated aortic valve procedure. Concomitant procedures were aortic root remodeling $(n=9)$, partial aortic arch replacement $(n=6)$, coronary artery bypass grafting $(\mathrm{n}=12)$, and mitral valve repair $(\mathrm{n}=1)$. All patients underwent full median sternotomy. The mean European System for Cardiac Operative Risk Evaluation II for the study population was $3.9 \pm 4.5$ (range, 0.6-28.6). The analysis of perioperative data showed a cardiopulmonary bypass time of $82 \pm 26$ minutes, an aortic crossclamping time of $59 \pm 21$ minutes, and surgical procedure duration of $161 \pm 46$ minutes. The duration of the inpatient stay was $9.5 \pm 4.3$ days. In comparison, the perioperative times of isolated aortic valve procedures $(\mathrm{n}=34)$ were shorter (cardiopulmonary bypass time, $72 \pm 20$ minutes; aortic crossclamping time, $53 \pm 17$ minutes; surgical procedure duration, $147 \pm 33$ minutes). No patients died during the investigation period, 5 patients developed postoperative delirium, and 2 patients received cardiopulmonary resuscitation, 1 of whom underwent reoperation because of secondary bleeding. Written informed consent was obtained from each study participant. The investigation was approved by the Ethics Committee of Saarland (Registration Number: 45/12).

\section{Parameters}

The study included a venous blood sample to determine the NT-proBNP value, the modified Borg Scale, the 6MWT, and 2 psychologic 
TABLE 1. Patient characteristics (absolute values and percentages)

\begin{tabular}{|c|c|}
\hline Patient characteristics & Patients $(n=60$ \\
\hline \multicolumn{2}{|l|}{ Preoperative clinical data } \\
\hline Age, y & $62 \pm 13$ \\
\hline Male sex & $45(75 \%)$ \\
\hline BMI, $\mathrm{kg} / \mathrm{m}^{2}$ & $28.7 \pm 5.4$ \\
\hline NYHA class I & $18(30.0 \%)$ \\
\hline NYHA class II & $25(41.7 \%)$ \\
\hline NYHA class III & $17(28.3 \%)$ \\
\hline \multicolumn{2}{|l|}{ Blood pressure, $\mathrm{mm} \mathrm{Hg}$} \\
\hline Systolic & $135 \pm 21$ \\
\hline Diastolic & $73 \pm 14$ \\
\hline Pulse, beats/min & $71 \pm 12$ \\
\hline \multicolumn{2}{|l|}{ Predominant aortic valve lesion } \\
\hline Aortic stenosis & $40(66.7 \%)$ \\
\hline Aortic regurgitation & $20(33.3 \%)$ \\
\hline \multicolumn{2}{|l|}{ Echocardiographic parameters } \\
\hline Ejection fraction, $\%$ & $64.1 \pm 15.2$ \\
\hline LVEDD, mm & $54.0 \pm 7.2$ \\
\hline LVESD, mm & $36.0 \pm 6.3$ \\
\hline \multicolumn{2}{|l|}{ Cardiovascular risk factors } \\
\hline Obesity (BMI $\geq 30$ ) & $23(38.3 \%)$ \\
\hline Arterial hypertension & $51(85 \%)$ \\
\hline Diabetes mellitus & $17(28.3 \%)$ \\
\hline Hyperlipidemia & $40(66.7 \%)$ \\
\hline Smoking & $15(25 \%)$ \\
\hline \multicolumn{2}{|l|}{ Medical history } \\
\hline Coronary artery disease & $19(31.7 \%)$ \\
\hline History of percutaneous coronary intervention & $6(10 \%)$ \\
\hline History of aortic or cardiac surgery & $7(11.7 \%)$ \\
\hline Carotid artery stenosis $\geq 50 \%$ & $3(5 \%)$ \\
\hline Peripheral occlusive disease & $3(5 \%)$ \\
\hline Chronic obstructive pulmonary disease & $5(8.3 \%)$ \\
\hline Pulmonary hypertension & $14(23.3 \%)$ \\
\hline Sleep apnea & $1(1.7 \%)$ \\
\hline Atrial fibrillation & $9(15 \%)$ \\
\hline Cardiac pacemaker & $2(3.3 \%)$ \\
\hline \multicolumn{2}{|l|}{ Preoperative medication } \\
\hline ACE inhibitors/ARBs & $37(61.7 \%)$ \\
\hline Beta-blockers & $45(75 \%)$ \\
\hline Diuretics & $23(38.3 \%)$ \\
\hline \multicolumn{2}{|l|}{ Morphology of the aortic valve } \\
\hline Unicuspid & $2(3.3 \%)$ \\
\hline Bicuspid & $24(40 \%)$ \\
\hline Tricuspid & $34(56.7 \%)$ \\
\hline
\end{tabular}

BMI, Body mass index; NYHA, New York Heart Association; $L V E D D$, left ventricular end-diastolic diameter; $L V E S D$, left ventricular end-systolic diameter; $A C E$, angiotensin-converting enzyme; $A R B$, angiotensin receptor blocker.

questionnaires (SF-12, HADS). Quantitative determination of the NTproBNP value was measured by using an electro-chemiluminescent immunoassay using the Elecsys 2010 analyzer (Roche Diagnostics, Indianapolis, Ind). ${ }^{18}$ The gender- and age-specific reference values published by Roche Diagnostics ${ }^{18}$ were used to compare it with the NT-proBNP values of this study population.

To assess symptoms of breathlessness, the patients were asked to quantify their extent of dyspnea by using the modified Borg Scale before every 6MWT. The modified Borg Scale measures the subjective feeling of difficulty of breathing on a numeric scale from 0 (nothing at all) to 10 (maximal).
The 6MWT was executed according to the recommendations of the American Thoracic Society. ${ }^{19}$ The 6-minute walk distance was compared with a normative value calculated by a gender- and age-specific equation by Troosters and colleagues. ${ }^{20}$

Assessment of health-related QoL was performed using the German version of the SF-12. ${ }^{21}$ The 12 items measure self-reported physical and mental health on particular scales. The scale ranges from 0 (worst $\mathrm{QoL}$ ) to 100 (best QoL). The results were compared with published age-matched normative values of a healthy population. ${ }^{21}$ Anxiety and depression were analyzed using the German version of the HADS. ${ }^{22}$ Both anxiety and depression subscales comprise 7 items each with a range from 0 (no anxiety/depression) to 21 (severe anxiety/depression). The scores were compared with a normative value calculated by a gender- and age-specific equation that was published by Hinz and Brahler. ${ }^{23}$ The calculation for the anxiety norm score was performed with the following equation: $2930+$ (female proportion $) \times 0.608+($ mean age $) \times 0.0168$ and for the depression norm score: $1749+($ female proportion $) \times(-) 0.115+($ mean age $) \times 0.063{ }^{23}$

The patients were investigated in the week before surgery and 1 week postoperatively before being discharged to a rehabilitation facility. Further assessments were conducted monthly until 6 months after AVS. The first follow-up after discharge (week 5) included only 28 patients because the majority of the study population were in a rehabilitation facility.

\section{Statistical Analysis}

Clinical data are presented as mean \pm standard deviation unless otherwise specified. Linear mixed models were used to model outcome variables, with random intercepts and slopes for patients. Time was treated as a continuous variable for deviations from linear time course postoperatively. Polynomial trends were considered, and model selection was based on likelihood ratio tests for nested models or Bayesian information criterion for non-nested models. Study time was set to have its origin at the first postoperative measurement. A structural break was allowed for preoperative measurements using a dummy coding. Changes from baseline (ie, preoperative values) were analyzed in a similar manner and analyzed adjusted for age and sex. Confidence limits were derived from posterior simulations of the fitted models. This flexible approach allowed an easy inversion of the fitted results to estimate the "time to recovery of baseline level" and respective confidence intervals (CIs) from the change from baseline models. All analyses were performed using R 3.2.3.

\section{RESULTS}

\section{Dyspnea (Modified Borg Scale)}

The subjective feeling of dyspnea (Figure 1) increased significantly by 0.54 points $(P=.003)$ at 1 week postoperatively compared with baseline. In comparison with the first week postoperatively, dyspnea decreased significantly starting with 0.24 points per week and following a cubic time trend. At 2.67 weeks $(95 \%$ CI, 0.95-4.73) after the first postoperative week, baseline level was restored, and after 4.73 weeks, the dyspnea was significantly better than preoperatively for the first time. Compared with preoperative dyspnea, after 6 months the Borg scale was significantly decreased by 0.54 points $(95 \% \mathrm{CI},-0.81$ to $-0.29)(P<.001)$. In comparison with the first week postoperatively, the Borg scale decreased within 3 months by 1.11 points $(95 \% \mathrm{CI},-1.41$ to -0.82$)(P<.001)$.

\section{Six-Minute Walk Test}

Of 60 patients, 10 were mildly restricted during the 6MWT because of arthrosis of the knee or hip $(n=7)$ or 


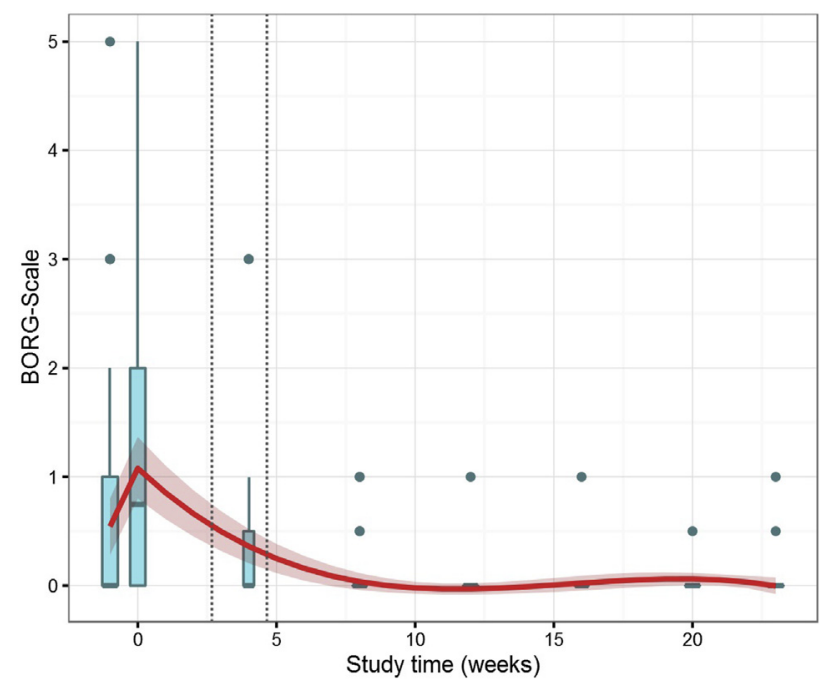

FIGURE 1. Changes in Borg scale over time. Boxplots of observed values with width of box proportional to sample size. Estimated marginal means (red line) and confidence limits from the fitted mixed model. Dotted vertical lines are (1) "time to restore preoperative level" and (2) "first time significantly better than preoperative level."

peripheral occlusive disease $(n=3)$. However, each of the 60 patients performed the 6MWT according to the study protocol. There was a significant impairment of the 6minute walk distance (Figure 2) from baseline to the first week postoperatively $(-133.88 \mathrm{~m} ; P<.001)$. Afterward, the 6 MWT increased significantly by initially $39.13 \mathrm{~m}$ per week (95\% CI, 31.95-46.31). This effect was moderated by a quadratic and cubic time effect. The preoperative walking distance was restored at $4.55(95 \%$ CI, 3.70-5.48) after the first postoperative week. Compared

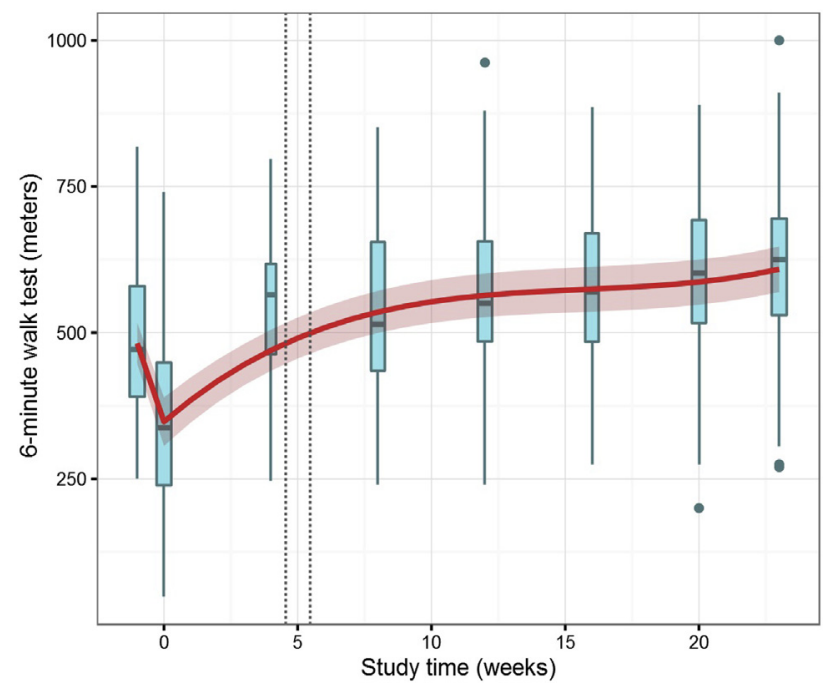

FIGURE 2. Changes in 6MWT over time. Boxplots of observed values with width of box proportional to sample size. Estimated marginal means (red line) and confidence limits from the fitted mixed model. Dotted vertical lines are (1) "time to restore preoperative level" and (2) "first time significantly better than preoperative level."

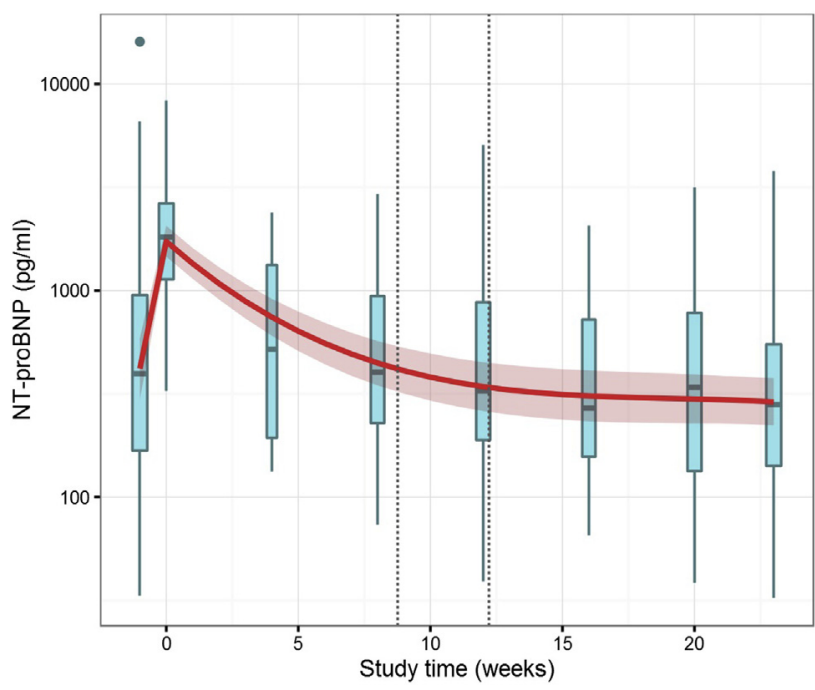

FIGURE 3. Changes in NT-proBNP (logarithmic scale) over time. Boxplots of observed values with width of box proportional to sample size. Estimated marginal means (red line) and confidence limits from the fitted mixed model. Dotted vertical lines are (1) "time to restore preoperative level" and (2) "first time significantly better than preoperative level." $N T$-proBNP, N-terminal pro-B-type natriuretic peptide.

with baseline, after 6 months postoperatively the 6MWT was significantly increased by $127.99 \mathrm{~m}(95 \% \mathrm{CI}$, $104.89-150.95 ; P<.001)$. At 5.48 weeks after the first postoperative week, the 6MWT was significantly better than baseline for the first time. In comparison with the first week postoperatively, the 6MWT increased significantly within 3 months by $212.39 \mathrm{~m}$ (95\% CI, 182.18-243.24; $P<.001$ ). At 6 months, the $6 \mathrm{MWT}$ was slightly inferior compared with published standard values of the healthy population $^{20}$ (610 vs $\left.658 \mathrm{~m} ; P=.001\right)$.

\section{N-Terminal Pro-B-type Natriuretic Peptide}

After 1 week postoperatively, NT-proBNP value (Figure 3) increased significantly by 4.13 times compared with the baseline value of $419.09 \mathrm{pg} / \mathrm{mL}(P<.001)$. Within 1 week, the NT-proBNP showed a significant decline of $33 \%$ $(P<.001)$; this rate was attenuated according to a thirdorder polynomial. After 6 months, NT-proBNP significantly decreased to $69 \%$ (95\% CI, 0.54-0.88) of the preoperative value $(P=.004)$. Compared with the first week postoperatively, NT-proBNP decreased within 3 months to $21 \%$ (95\% CI, 0.17-0.26) of the postoperative value at 1 week $(P<.001)$ (meaning that after 3 months postoperatively NT-proBNP was 5 times lower than the level at the first week postoperatively). Compared with all assessed physical parameters, NT-proBNP showed a delayed recovery. Baseline values were achieved at 8.77 weeks $(95 \% \mathrm{CI}, 6.44-12.11)$ after the first postoperative week. NT-proBNP was significantly better than preoperatively for the first time at 12.11 weeks after the first postoperative measurement. 

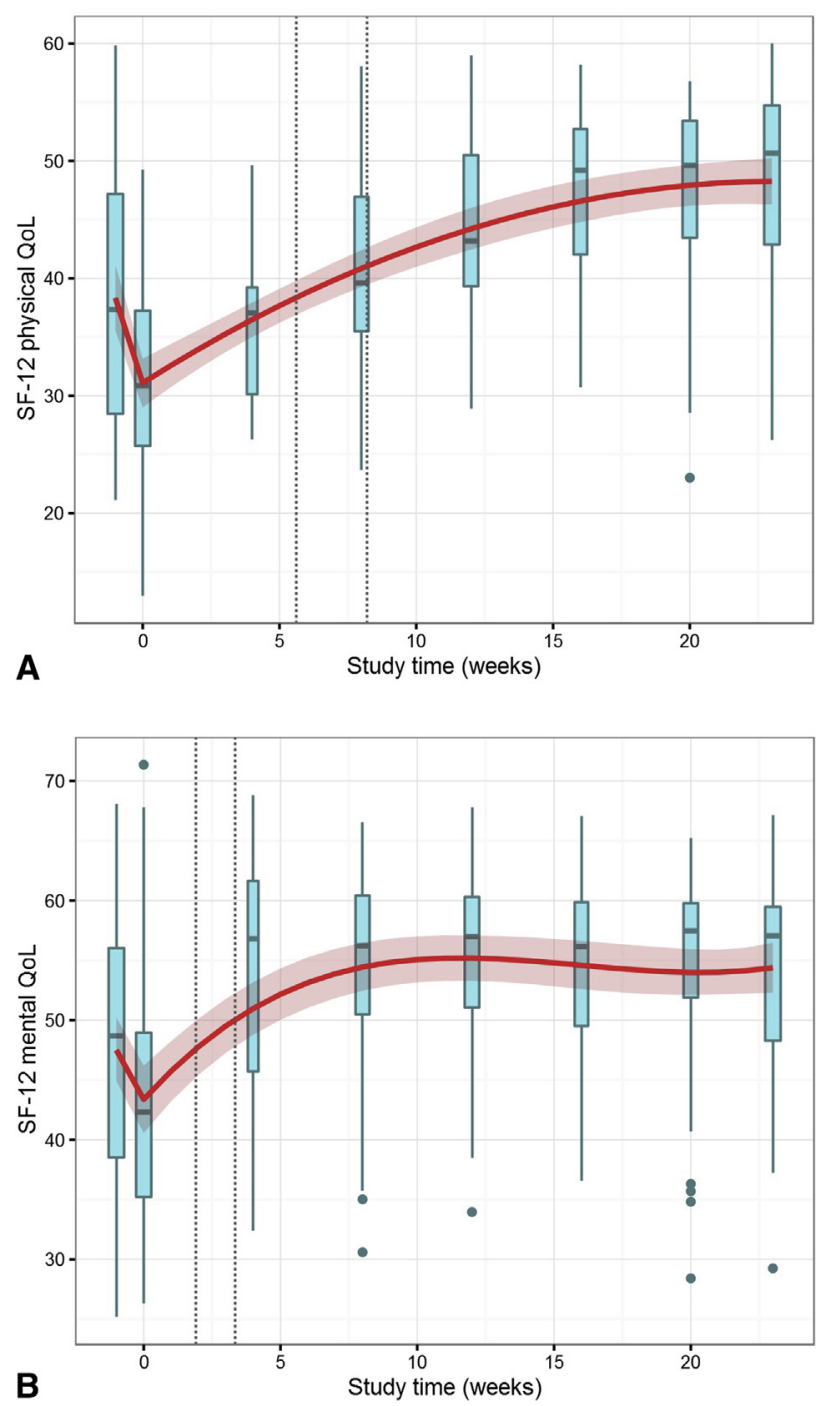

FIGURE 4. Changes in SF-12 physical QoL (A) and SF-12 mental QoL (B) over time. Boxplots of observed values with width of box proportional to sample size. Estimated marginal means (red line) and confidence limits from the fitted mixed model. Dotted vertical lines are (1) "time to restore preoperative level" and (2) "first time significantly better than preoperative level." $S F-12,12$-item Short Form Health Survey; $Q o L$, quality of life.

\section{Health-Related Quality of Life (12-Item Short Form Health Survey)}

The physical QoL (Figure 4, $A$ ) decreased significantly by 7.23 points $(P<.001)$ at 1 week postoperatively compared with the preoperative value of 38.33 . It increased afterward starting with 1.47 points per week $(P<.001)$; this rate decreased significantly according to a second-order term of -0.03 , for example, the slope decreased by -0.06 points per week. The estimated time to restore preoperative values was 5.62 weeks (95\% CI, 3.63-8.13) after the first postoperative week. The physical QoL was significantly better than baseline for the first time at 8.13 weeks after the first postoperative measurement. Compared with baseline, after
6 months the physical QoL was significantly increased by 10.00 points $(95 \% \mathrm{CI}, 7.50-12.52 ; P<.001)$. Compared with the first week postoperatively, physical health increased within 3 months by 12.38 points $(95 \%$ CI, 9.78 $14.92 ; P<.001)$. Furthermore, physical QoL at 6 months postoperatively was significantly higher compared with age-matched published norms ${ }^{21}$ (48.4 vs $44.3 ; P<.001$ ).

In regard to mental QoL (Figure $4, B$ ), there was a significant decline by 4.15 points $(P=.003)$ at 1 week postoperatively compared with the baseline value of 47.54 . Mental QoL increased afterward starting with 2.52 points per week $(P<.001)$. This rate decreased significantly according to a third-order polynomial. At 1.90 weeks $(95 \% \mathrm{CI}$, 0.69-3.36) after the first postoperative week, the preoperative mental QoL was restored; at 3.36 weeks after the first postoperative measurement, the mental QoL was significantly better than baseline for the first time. Compared with preoperatively, after 6 months the mental QoL was significantly increased by 6.86 points $(95 \%$ CI, 4.46-9.33; $P<.001$ ), and in comparison with the first week postoperatively, mental QoL increased within 3 months by 7.71 points (95\% CI, 3.67-13.54; $P<.001$ ). No differences compared with age-matched published norms ${ }^{21}$ were seen at 6 months postoperatively (54 vs $53.4 ; P=.535$ ).

\section{Anxiety and Depression (Hospital Anxiety and Depression Scale)}

Anxiety (Figure 5, $A$ ) did not change significantly from the preoperative value of 6.07 to the first week postoperatively $(+0.60 ; P=.208)$. Afterward, there was a significant decline by 0.92 points within the first week $(P<.001)$, which was then attenuated according to a third-order polynomial. The preoperative anxiety was already restored at 0.64 weeks ( $95 \% \mathrm{CI},-0.43$ to 1.68$)$ after the first postoperative measurement, and anxiety was significantly better than baseline for the first time at 1.68 weeks after the first postoperative week. After 6 months postoperatively, anxiety was significantly decreased by 2.99 points $(95 \% \mathrm{CI},-3.88$ to -2.09$)$ in comparison with anxiety at baseline $(P<.001)$. Compared with the first week postoperatively, anxiety decreased within 3 months by 3.74 points $(95 \% \mathrm{CI},-4.71$ to $-2.76 ; P<.001)$. The anxiety score 6 months after AVS was significantly lower than the calculated normative value ${ }^{23}(4.1$ vs $3.2 ; P=.039)$.

Depression (Figure $5, B$ ) increased significantly at 1 week postoperatively by 1.10 points $(P=.008)$ when compared with the preoperative value of 5.10. After the first week, there was a significant decline by 0.76 points $(P<.001)$. This decline was reduced in time course according to a thirdorder polynomial fit. The expected time to restore preoperative values was 1.57 weeks ( $95 \%$ CI, 0.44-2.80) after the first postoperative week. Postoperative depression was better than baseline for the first time at 2.8 weeks after the first postoperative measurement. In relation to preoperative values, depression at 6 months postoperatively was significantly decreased 

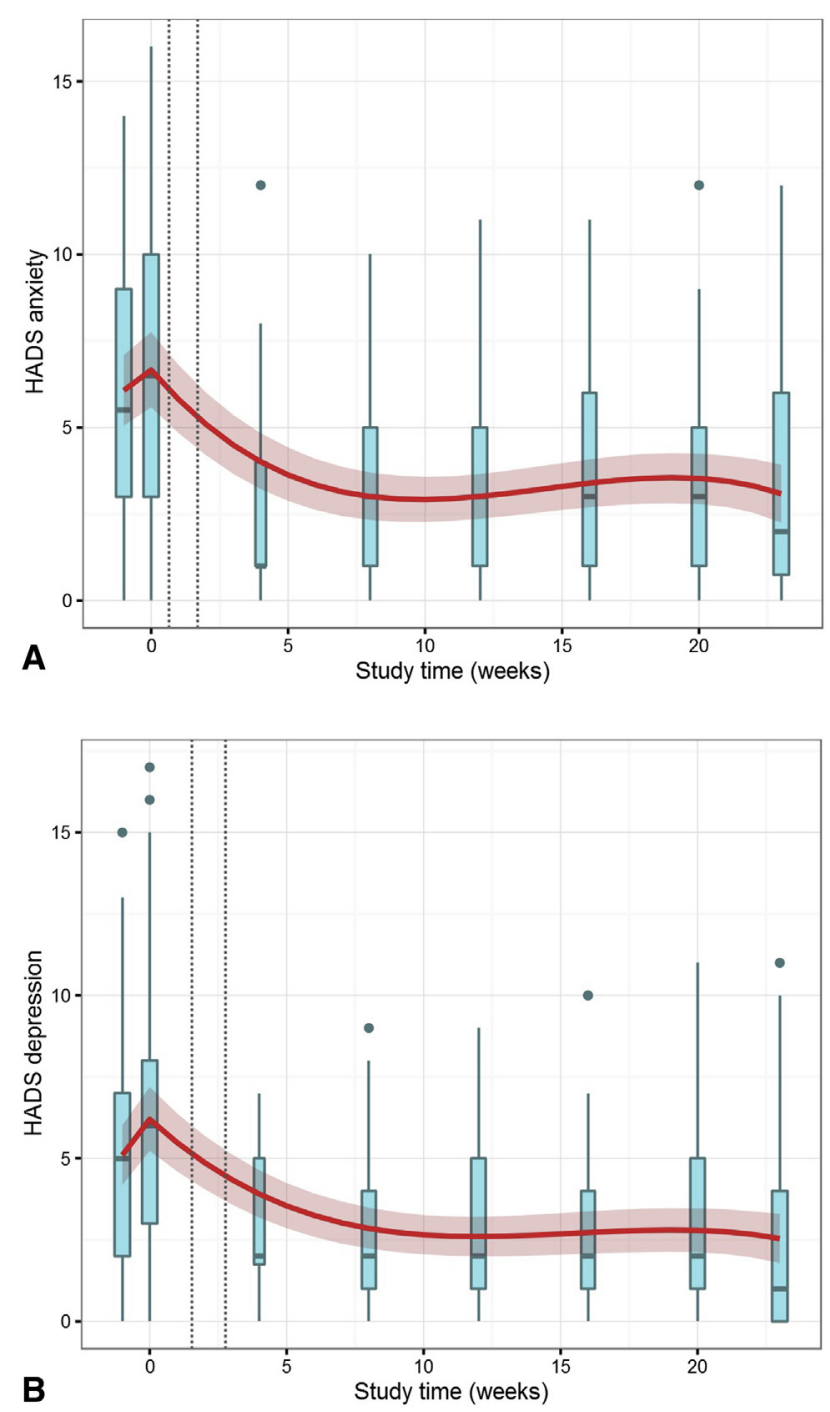

FIGURE 5. Changes in HADS anxiety (A) and HADS depression (B) over time. Boxplots of observed values with width of box proportional to sample size. Estimated marginal means (red line) and confidence limits from the fitted mixed model. Dotted vertical lines are (1) "time to restore preoperative level" and (2) "first time significantly better than preoperative level." HADS, Hospital Anxiety and Depression Scale.

by 2.56 points ( $95 \% \mathrm{CI},-3.29$ to $-1.81 ; P<.001)$, and in comparison with postoperative values, depression decreased within 3 months by 3.62 points $(95 \% \mathrm{CI},-4.51$ to -2.69 ; $P<.001)$. The depression score at 6 months after AVS was significantly lower than the calculated normative value ${ }^{23}$ (2.6 vs $5.6 ; P<.001)$.

\section{Adjusted Analysis}

Analysis was adjusted for age (split by median) and sex. We started with an initial model including all 2-way interactions between polynomial time trend and adjustment variables and performed a backward selection. According to this procedure, the interaction between linear time trend and age was significant for SF-12 physical QoL, that is, a lower postoperative decline but a lower gradient, which indicated an earlier recovery for the older group, and for NT-proBNP time, the trend was significantly different for age groups, indicating a lower impact postoperatively but a slightly lower reduction rate of NT-proBNP in the older group, resulting in comparable time to restoring preoperative values. However, because these tests were not prespecified, these findings are tentative and further research is needed. No other interactions were found, and adjustment changed little compared with the unadjusted estimates of time trends (Tables E1-E7).

\section{DISCUSSION}

Surgical treatment of the aortic valve involves many physiologic changes and requires physical and mental adjustments by the patient. Most previous studies have focused on survival and cardiac aspects of recovery, 2,3 including left ventricular remodeling after aortic valve interventions. ${ }^{24}$ Although the recovery after AVS is influenced by preoperative factors (eg, left ventricular ejection fraction, New York Heart Association classification, and renal function) and perioperative factors (eg, myocardial ischemia resulting in ventricular impairment and type of surgical procedure), general somatic and psychic implications have to be considered in the recovery process. Some studies indicated different psychologic manifestations in regard to the cardiovascular disease and treatment. Bayer-Topilsky and colleagues ${ }^{25}$ implied a higher anxiety but equal QoL in patients with valve disease compared with patients with coronary artery disease. Other studies pointed out that patients were psychologically less ${ }^{26}$ or equally ${ }^{27}$ burdened after different types of cardiovascular surgery than healthy controls. Against this background, we investigated the course of physical and mental recovery with a particular focus on the monthly pattern and the point in time of completed recovery after conventional AVS.

Few studies have analyzed the 6MWT before and after AVS. ${ }^{7,8}$ In addition to assessing the recovery after AVS, the 6MWT has proven to be a prognostic marker for perioperative death or complications. ${ }^{6}$ Fiorina and colleagues ${ }^{7}$ documented the effect of postoperative rehabilitation, although the study was limited in time ( 2 weeks) and performed primarily in patients who underwent coronary bypass surgery $(67 \%$ coronary artery bypass grafting, $25 \%$ valve replacement, $4 \%$ both, $4 \%$ other). In addition, this parameter has not been studied systematically until assumed full recovery. We discovered a decrease in 6MWT 1 week after AVS, yet the mean values were higher in this study compared with others. ${ }^{7,8}$ This can be explained partially by the mean age of the different groups (our study: 62 years; Fiorina and colleagues ${ }^{7}: 65$ years; Russo and colleagues $^{8}: 82$ years). Further, the rapid improvement of the walking distance in this study has to be noted because a major recovery of 6MWT was achieved after 9 weeks. 
NT-proBNP has been established as a biomarker for cardiac dysfunction. ${ }^{9}$ Other studies ${ }^{10-12}$ and the current study have discovered a peak of the NT-proBNP value at 1 week after valve surgery. This elevation is related to surgical trauma, in particular the ventricular stunning seen after ischemia-reperfusion injury of the myocardium. ${ }^{28}$ We observed a gradual decrease over the subsequent months; at 6 months, mean NT-proBNP was essentially close to normal. These findings were similar to the results of other studies, ${ }^{11,12}$ although in those studies lower levels were observed between 6 and 12 months after surgery. ${ }^{11,12}$ Most of the preoperative values were similar (Song and colleagues ${ }^{11}$ : $508 \mathrm{pg} / \mathrm{mL}$ [aortic stenosis]; 1836 [aortic regurgitation]; Neverdal and colleagues ${ }^{12}$ : $283 \mathrm{pg} / \mathrm{mL})$ to our study $(419 \mathrm{pg} / \mathrm{mL})$. The distinction may be related to differences in patient population and main indication (eg, aortic stenosis ${ }^{12}$ ), and possibly to the timing of NT-proBNP measurement (12 months after $\mathrm{AVS}^{11}$ ). Similar to the 6MWT, the NT-proBNP value decreased consecutively until 6 months, proving that physical recovery continues until at least 6 months after surgery. Of all studied parameters, NT-proBNP was the last to reach a value better than baseline at 12 weeks.

An accepted tool to assess QoL is the SF-12 questionnaire. ${ }^{13}$ In mixed patient cohorts (37\% coronary artery bypass grafting, 26\% AVS, 25\% mitral valve surgery, 12\% Maze procedure), improvement of physical and mental QoL was discovered over the first 3 to 6 months. ${ }^{29}$ Marked improvement compared with preoperative conditions was detected 18 months after AVS.${ }^{14}$ Our results were in line with those of previous studies. ${ }^{14,29}$ In this study, physical recovery and recovery in physical QoL showed similar patterns, indicating progressive improvement until 6 months after AVS. At 6 months, the mean physical QoL was even higher than the age-matched published norms. ${ }^{21}$ This could be explained by a higher than average motivation level after a successful surgery, resulting in a subjective feeling superior to that of the healthy population. On the other hand, mental QoL improved more rapidly. At 5 weeks, mental QoL was similar to the 6-month values and to sex- and age-matched published norms. ${ }^{21}$ Beyond that point, mental QoL remained stable. This important finding suggests that the immediate relieve of a successful surgery improves mental QoL right after surgery without any decline in the course of recovery.

Anxiety and depression have been identified to strongly influence postoperative recovery ${ }^{16,17}$ and can be determined by the HADS. ${ }^{22}$ They are influenced by many factors, among them the type of implant or intervention. ${ }^{30}$ Anxiety was not decreased at 1 week after surgery. Similar to mental QoL, anxiety was markedly reduced by 2 to 3 weeks. The results were almost identical for depression, with most recovery having taken place within the first postoperative weeks. For anxiety and depression, the 6-month values were better than gender- and age-matched published norms,${ }^{23}$ indicating a low probability of persisting posttraumatic disorders. At baseline, the prevalence of depression was not higher compared with healthy published norms, showing that coping mechanisms were already taking place before the upcoming conventional AVS. In contrast, the patients in this study were more anxious before surgery than healthy published norms, which can be explained by the fear of the forthcoming cardiac surgery.

In addition to mental recovery, dyspnea (a subjective feeling of breathlessness) measured by the modified Borg scale showed an early recovery at 5 weeks postoperatively.

The results of this study indicate that mental recovery is achieved significantly fast 4 to 6 weeks after AVS with an exception for physical QoL showing a continued recovery until 6 months. Similar findings have been made for physical recovery. Although the 6MWT distance was already better than baseline at 5 weeks, the physical QoL and NTproBNP value seemed to lag behind.

These findings were observed in a study population treated with conventional AVS. New approaches in the treatment of aortic valve disease have been made recently. Transcatheter aortic valve implantation (TAVI) via a transfemoral or transapical approach and aortic valve repair are new and promising treatments of aortic valve disease. Some studies have compared conventional AVS with TAVI, showing a higher rate of perioperative complications in the TAVI group. ${ }^{31}$ Other studies compared the transaortic with the transapical approach, ${ }^{32}$ showing equivalent rates of mortality and complications. However, future studies need to assess differences in the recovery process after different types of AVS.

\section{Study Limitations}

A study limitation is that the patients performed the 6MWT for the first time. It is well known that the 6MWT can be familiarized after repeated performances. ${ }^{33}$ However, because of the time limitation and patients' endurance, the 6MWT was performed only once per appointment. Therefore, it is not excluded that some of the improved distance can be explained by the training effect of the 6MWT procedure. Furthermore, $17 \%$ of the patients were slightly restricted during the 6MWT because of arthrosis of the knee or hip or peripheral occlusive disease. However, none of those patients had to take a break during the 6MWT nor did the disease worsen over the investigation period. Moreover, 28 patients had concomitant procedures that might have affected the physical and mental recovery. In addition, the baseline QoL, anxiety, and depression scores were obtained in the week before surgery and may have been artificially worsened in view of the upcoming surgery. However, the patients were asked about their status in the last 4 weeks before surgery to minimize the effect of fear of the upcoming surgery on the preoperative data. Nevertheless, the response bias is an unavoidable limitation when using such questionnaires. 


\section{CONCLUSIONS}

This study is the first to report the monthly course of physical and mental recovery after conventional AVS. A significant impairment of all measured parameters was seen at 1 week after AVS. Beyond the first postoperative week, the most pronounced physical and mental recovery were achieved in the first 4 to 6 weeks after AVS. A full mental recovery was achieved after 3 to 5 weeks. The 6MWT distance, NT-proBNP, and physical QoL continued to improve until 6 months, with a delayed recovery of physical QoL and especially NT-proBNP. Physical and mental QoL, and anxiety and depression scores were significantly better or similar when compared with published healthy standard values. Further research will have to focus on intervention-specific differences (aortic valve repair vs replacement, TAVI vs conventional AVS) regarding the recovery process.

\section{Conflict of Interest Statement}

Authors have nothing to disclose with regard to commercial support.

\section{References}

1. Iung B, Baron G, Tornos P, Gohlke-Barwolf C, Butchart EG, Vahanian A Valvular heart disease in the community: a European experience. Curr Probl Cardiol. 2007;32:609-61

2. Joint Task Force on the Management of Valvular Heart Disease of the European Society of Cardiology (ESC); European Association for Cardio-Thoracic Surgery (EACTS), Vahanian A, Alfieri O, Andreotti F, Antunes MJ, BarónEsquivias G, Baumgartner H, et al. Guidelines on the management of valvular heart disease (version 2012). Eur Heart J. 2012;33:2451-96.

3. Hammermeister K, Sethi GK, Henderson WG, Grover FL, Oprian C, Rahimtoola SH. Outcomes 15 years after valve replacement with a mechanical versus a bioprosthetic valve: final report of the Veterans Affairs randomized trial. J Am Coll Cardiol. 2000;36:1152-8.

4. Price J, De Kerchove L, Glineur D, Vanoverschelde JL, Noirhomme P, El Khoury G. Risk of valve-related events after aortic valve repair. Ann Thorac Surg. 2013;95:606-13.

5. Solway S, Brooks D, Lacasse Y, Thomas S. A qualitative systematic overview of the measurement properties of functional walk tests used in the cardiorespiratory domain. Chest. 2001;119:256-70.

6. de Arenaza DP, Pepper J, Lees B, Rubinstein F, Nugara F, Roughton M, et al. Preoperative 6-minute walk test adds prognostic information to Euroscore in patients undergoing aortic valve replacement. Heart. 2010;96:113-7.

7. Fiorina C, Vizzardi E, Lorusso R, Maggio M, De Cicco G, Nodari S, et al. The 6min walking test early after cardiac surgery. Reference values and the effects of rehabilitation programme. Eur J Cardiothorac Surg. 2007;32:724-9.

8. Russo N, Compostella L, Tarantini G, Setzu T, Napodano M, Bottio T, et al. Cardiac rehabilitation after transcatheter versus surgical prosthetic valve implantation for aortic stenosis in the elderly. Eur J Prev Cardiol. 2014;21:1341-8.

9. Maisel AS, Krishnaswamy P, Nowak RM, McCord J, Hollander JE, Duc P, et al. Rapid measurement of B-type natriuretic peptide in the emergency diagnosis of heart failure. N Engl J Med. 2002;347:161-7.

10. Cai B, Wang L, Liu J, Shi Y, Guo Y. N-terminal pro-Brain natriuretic peptide as a useful biomarker for monitoring prognosis in patients with cardiac valve replacement. J Clin Lab Anal. 2011;25:149-55.

11. Song BG, Park YH, Kang GH, Chun WJ, Oh JH, Choi JO, et al. Preoperative, postoperative and one-year follow-up of N-terminal pro-B-type natriuretic peptide levels in volume overload of aortic regurgitation: comparison with pressure overload of aortic stenosis. Cardiology. 2010;116:286-91.

12. Neverdal NO, Knudsen CW, Husebye T, Vengen ØA, Pepper J, Lie M, et al. The effect of aortic valve replacement on plasma B-type natriuretic peptide in patients with severe aortic stenosis-one year follow-up. Eur J Heart Fail. 2006;8:257-62.
13. Bullinger M. Erfassung der gesundheitsbezogenen Lebensqualität mit dem SF36-Health Survey. Bundesgesundheitsbl - Gesundheitsforsch - Gesundheits schutz. 2000;43:190-7.

14. Sedrakyan A, Hebert P, Vaccarino V, Paltiel AD, Elefteriades JA, Mattera J, et al. Quality of life after aortic valve replacement with tissue and mechanical implants. J Thorac Cardiovasc Surg. 2004;128:266-72.

15. Herrmann C. International experiences with the Hospital Anxiety and Depression Scale-a review of validation data and clinical results. J Psychosom Res. 1997;42: $17-41$.

16. Williams JB, Alexander KP, Morin JF, Langlois Y, Noiseux N, Perrault LP, et al. Preoperative anxiety as a predictor of mortality and major morbidity in patients aged >70 years undergoing cardiac surgery. Am J Cardiol. 2013;111:137-42.

17. Ho PM, Masoudi FA, Spertus JA, Peterson PN, Shroyer AL, McCarthy M, et al. Depression predicts mortality following cardiac valve surgery. Ann Thorac Surg. 2005;79:1255-9.

18. Roche Diagnostics: proBNP II - N-terminal pro B-type natriuretic peptide (cobas $\left.{ }^{\circledR}\right)$. Available at: http://www.rochecanada.com/content/dam/internet/corpo rate/rochecanada/en_CA/documents/package_inserts/ProBNPII-04842464190EN-V9-CAN.pdf. Accessed June 21, 2015.

19. ATS Committee on Proficiency Standards for Clinical Pulmonary Function Laboratories. ATS statement: guidelines for the six-minute walk test. Am J Respir Crit Care Med. 2002;166:111-7.

20. Troosters T, Gosselink R, Decramer M. Six minute walking distance in healthy elderly subjects. Eur Respir J. 1999;14:270-4.

21. Bullinger M, Kirchberger I. SF-36 Fragebogen zum Gesundheitszustand. Handanweisung. Göttingen: Hogrefe-Verlag GmbH \& Co KG; 1998.

22. Herrmann-Lingen C, Buss U, Snaith RP. HADS-D Hospital and Anxiety and Depression Scale-Deutsche Version. Ein Fragebogen zur Erfassung von Angst und Depressivität in der somatischen Medizin. Testdokumentation und Handanweisung (HADS-D Hospital Anxiety and Depression Scale-German Version. A Questionnaire to Assess Anxiety and Depression in Somatic Medicine. Test Documentation and Manual). Bern: Huber; 1995.

23. Hinz A, Brahler E. Normative values for the hospital anxiety and depression scale (HADS) in the general German population. J Psychosom Res. 2011;71:74-8.

24. Biederman RW, Magovern JA, Grant SB, Williams RB, Yamrozik JA, Vido DA, et al. LV reverse remodeling imparted by aortic valve replacement for severe aortic stenosis; is it durable? A cardiovascular MRI study sponsored by the American Heart Association. J Cardiothorac Surg. 2011;6:53.

25. Bayer-Topilsky T, Suri RM, Topilsky Y, Marmor YN, Trenerry MR, Antiel RM, et al. Psychoemotional and quality of life response to mitral operations in patients with mitral regurgitation: a prospective study. Ann Thorac Surg. 2015;99:847-54

26. Timberlake N, Klinger L, Smith P, Venn G, Treasure T, Harrison M, et al. Incidence and patterns of depression following coronary artery bypass graft surgery J Psychosom Res. 1997:43:197-207.

27. Urso S, Sadaba R, Vives M, Beltrame S, Trujillo J, Aldamiz-Echevarria G. Quality of life en elderly patients undergoing aortic valve replacement: a comparative study with the general Spanish population. Med Clin (Barc). 2009;133:422-4.

28. Georges A, Forestier F, Valli N, Plogin A, Janvier G, Bordenave L. Changes in type B natriuretic peptide (BNP) concentrations during cardiac valve replacement. Eur J Cardiothorac Surg. 2004;25:941-5.

29. Grady KL, Lee R, Subacius H, Malaisrie C, McGee EC, Kruse J, et al. Improve ments in health-related quality of life before and after isolated cardiac operations Ann Thorac Surg. 2011;91:777-83.

30. Aicher D, Holz A, Feldner S, Kollner V, Schafers HJ. Quality of life after aortic valve surgery: replacement versus reconstruction. J Thorac Cardiovasc Surg. 2011;142:e19-24.

31. Muneretto C, Bisleri G, Moggi A, Di Bacco L, Tespili M, Repossini A, et al, Treating the patients in the 'grey-zone' with aortic valve disease: a comparison among conventional surgery, sutureless valves and transcatheter aortic valve replacement. Interact Cardiovasc Thorac Surg. 2015;20:90-5.

32. Dunne B, Tan D, Chu D, Yau V, Xiao J, Ho KM, et al. Transapical versus transaortic transcatheter aortic valve implantation: a systematic review. Ann Thorac Surg. 2015;100:354-61.

33. Kervio G, Carre F, Ville NS. Reliability and intensity of the six-minute walk test in healthy elderly subjects. Med Sci Sports Exerc. 2003;35:169-74.

Key Words: aortic valve surgery, recovery, proBNP, 6-minute walk test, quality of life, anxiety, depression 
TABLE E1. Adjusted analysis of modified Borg scale

\begin{tabular}{|c|c|c|c|c|c|c|}
\hline \multirow[b]{2}{*}{ Effect } & \multicolumn{3}{|c|}{ Model 1} & \multicolumn{3}{|c|}{ Model 2} \\
\hline & B & CI & $P$ & B & CI & $\boldsymbol{P}$ \\
\hline Change postoperatively* & 0.54 & $0.20-0.88$ & .003 & 0.62 & $0.17-1.07$ & .009 \\
\hline Linear time & -0.24 & -0.30 to -0.19 & $<.001$ & -0.24 & -0.32 to -0.16 & $<.001$ \\
\hline Squared time & 0.02 & 0.01-0.02 & $<.001$ & 0.02 & 0.01-0.02 & $<.001$ \\
\hline Cubic time & -0.00 & -0.00 to -0.00 & $<.001$ & -0.00 & -0.00 to -0.00 & $<.001$ \\
\hline Age greater than median & & & & -0.07 & -0.56 to 0.43 & .799 \\
\hline Female & & & & -0.18 & -0.77 to 0.40 & .544 \\
\hline
\end{tabular}

$B$, Estimated effect; $C I$, confidence interval. Bold signifies $P$ values below $5 \%$. Time is measured in weeks. The final model of the model selection process includes all terms up to a cubic time trend. Model 1 unadjusted model, model 2 adjusted for age and sex. *Intercept terms: For model 2, this is the value for young (age $<66$ years) man.

TABLE E2. Adjusted analysis of 6-minute walk test

\begin{tabular}{|c|c|c|c|c|c|c|}
\hline \multirow[b]{2}{*}{ Effect } & \multicolumn{3}{|c|}{ Model 1} & \multicolumn{3}{|c|}{ Model 2} \\
\hline & B & CI & $P$ & B & CI & $\boldsymbol{P}$ \\
\hline Change postoperatively* & -135.82 & -165.63 to -106.01 & $<.001$ & -116.78 & -154.29 to -79.27 & $<.001$ \\
\hline Linear time & 39.41 & $34.25-44.57$ & $<.001$ & 39.38 & $32.22-46.54$ & $<.001$ \\
\hline Squared time & -2.38 & -2.81 to -1.95 & $<.001$ & -2.38 & -2.97 to -1.80 & $<.001$ \\
\hline Cubic time & 0.05 & $0.04-0.06$ & $<.001$ & 0.05 & 0.04-0.07 & $<.001$ \\
\hline Age greater than median & & & & -37.41 & -71.94 to -2.89 & .038 \\
\hline Female & & & & -0.16 & -40.92 to 40.61 & .99 \\
\hline
\end{tabular}

$B$, Estimated effect; $C I$, confidence interval. Bold signifies $P$ values below $5 \%$. Time is measured in weeks. The final model of the model selection process includes all terms up to a cubic time trend. Model 1 unadjusted model, model 2 adjusted for age and sex. *Intercept terms: For model 2, this is the value for young (age $<66$ years) man.

TABLE E3. Adjusted analysis of N-terminal pro-B-type natriuretic peptide

\begin{tabular}{|c|c|c|c|c|c|c|}
\hline \multirow[b]{2}{*}{ Effect } & \multicolumn{3}{|c|}{ Model 1} & \multicolumn{3}{|c|}{ Model 2} \\
\hline & B & CI & $P$ & B & CI & $\boldsymbol{P}$ \\
\hline Change postoperatively* & 1.41 & 1.11-1.70 & $<.001$ & 1.88 & $1.49-2.26$ & $<.001$ \\
\hline Linear time & -0.25 & -0.30 to -0.20 & $<.001$ & -0.31 & -0.37 to -0.25 & $<.001$ \\
\hline Squared time & 0.01 & 0.01-0.02 & $<.001$ & 0.01 & 0.01-0.02 & $<.001$ \\
\hline Cubic time & -0.00 & -0.00 to -0.00 & .003 & -0.00 & -0.00 to -0.00 & .005 \\
\hline Age greater than median & & & & -0.85 & -1.39 to -0.31 & .003 \\
\hline Female & & & & -0.24 & -0.71 to 0.23 & .318 \\
\hline Linear time by age $\dagger$ & & & & 0.11 & $0.06-0.17$ & $<.001$ \\
\hline Squared time by age $\ddagger$ & & & & -0.00 & -0.01 to -0.00 & .001 \\
\hline
\end{tabular}

$B$, Estimated effect; $C I$, confidence interval. *For models 2 , this is the value for young (age 66 years) man. Bold signifies $P$ values below $5 \%$. Time is measured in weeks. Effects are on log-scale of N-terminal pro-B-type. The final model of the model selection process includes all terms up to a cubic time trend. Model 1 unadjusted model, model 2 adjusted for age and sex. †Linear time trend is altered by this value in the older group. †Quadratic time trend is altered by this value in the older group.

TABLE E4. Adjusted analysis of 12-Item Short Form Health Survey physical quality of life

\begin{tabular}{|c|c|c|c|c|c|c|}
\hline \multirow[b]{2}{*}{ Effect } & \multicolumn{3}{|c|}{ Model 1} & \multicolumn{3}{|c|}{ Model 2} \\
\hline & B & CI & $\boldsymbol{P}$ & B & CI & $P$ \\
\hline Change postoperatively* & -7.27 & -9.80 to -4.73 & $<.001$ & -11.88 & -15.24 to -8.52 & $<.001$ \\
\hline Linear time & 1.47 & $1.08-1.85$ & $<.001$ & 1.61 & $1.21-2.00$ & $<.001$ \\
\hline Squared time & -0.03 & -0.05 to -0.02 & $<.001$ & -0.03 & -0.05 to -0.02 & $<.001$ \\
\hline Age greater than median & & & & 7.15 & 2.64-11.65 & .003 \\
\hline Female & & & & 4.55 & -0.17 to 9.27 & .064 \\
\hline Interaction time by age $\dagger$ & & & & -0.28 & -0.48 to -0.08 & .009 \\
\hline
\end{tabular}

$B$, Estimated effect; $C I$, confidence interval. *For models 2 and 3, this is the value for young (age 66 years) man. Bold signifies $P$ values below $5 \%$. Time is measured in weeks. The final model of the model selection process includes a linear and a quadratic time trend. Model 1 unadjusted model, model 2 adjusted for age and sex. $\dagger$ Linear time trend is altered by this value in the older group. 
TABLE E5. Adjusted analysis of 12-Item Short Form Health Survey mental quality of life

\begin{tabular}{|c|c|c|c|c|c|c|}
\hline \multirow[b]{2}{*}{ Effect } & \multicolumn{3}{|c|}{ Model 1} & \multicolumn{3}{|c|}{ Model 2} \\
\hline & B & CI & $\boldsymbol{P}$ & B & CI & $P$ \\
\hline Change postoperatively* & -4.16 & -6.82 to -1.49 & .003 & -1.74 & -4.98 to 1.50 & .297 \\
\hline Linear time & 2.49 & $1.80-3.19$ & $<.001$ & 2.49 & $1.80-3.18$ & $<.001$ \\
\hline Squared time & -0.17 & -0.24 to -0.10 & $<.001$ & -0.17 & -0.24 to -0.10 & $<.001$ \\
\hline Cubic time & 0.00 & $0.00-0.01$ & .001 & 0.00 & $0.00-0.01$ & .001 \\
\hline Age greater than median & & & & -6.05 & -9.79 to -2.32 & .002 \\
\hline Female & & & & 2.04 & -2.27 to 6.35 & .358 \\
\hline
\end{tabular}

TABLE E6. Adjusted analysis of Hospital Anxiety and Depression Scale anxiety

\begin{tabular}{|c|c|c|c|c|c|c|}
\hline \multirow[b]{2}{*}{ Effect } & \multicolumn{3}{|c|}{ Model 1} & \multicolumn{3}{|c|}{ Model 2} \\
\hline & B & CI & $\boldsymbol{P}$ & B & CI & $\boldsymbol{P}$ \\
\hline Change postoperatively* & 0.60 & -0.32 to 1.52 & .205 & -0.75 & -1.83 to 0.32 & .174 \\
\hline Linear time & -0.91 & -1.11 to -0.72 & $<.001$ & -0.94 & -1.19 to -0.68 & $<.001$ \\
\hline Squared time & 0.07 & 0.05-0.09 & $<.001$ & 0.07 & 0.05-0.10 & $<.001$ \\
\hline Cubic time & -0.00 & -0.00 to -0.00 & $<.001$ & -0.00 & -0.00 to -0.00 & $<.001$ \\
\hline Age greater than median & & & & 2.73 & $1.50-3.96$ & $<.001$ \\
\hline Female & & & & 0.04 & -1.37 to 1.46 & .954 \\
\hline
\end{tabular}

$B$, Estimated effect; $C I$, confidence interval. Bold signifies $P$ values below $5 \%$. Time is measured in weeks. The final model of the model selection process includes all terms up to a cubic time trend. Model 1 unadjusted model, model 2 adjusted for age and sex. *Intercept terms: For model 2, this is the value for young (age $<66$ years) man.

TABLE E7. Adjusted analysis of Hospital Anxiety and Depression Scale depression

\begin{tabular}{|c|c|c|c|c|c|c|}
\hline \multirow[b]{2}{*}{ Effect } & \multicolumn{3}{|c|}{ Model 1} & \multicolumn{3}{|c|}{ Model 2} \\
\hline & B & CI & $\boldsymbol{P}$ & B & CI & $P$ \\
\hline Change postoperatively* & 1.10 & $0.31-1.89$ & .008 & 0.33 & -0.64 to 1.29 & .510 \\
\hline Linear time & -0.76 & -0.93 to -0.58 & $<.001$ & -0.78 & -1.01 to -0.55 & $<.001$ \\
\hline Squared time & 0.05 & 0.04-0.07 & $<.001$ & 0.05 & 0.03-0.07 & $<.001$ \\
\hline Cubic time & -0.00 & -0.00 to -0.00 & $<.001$ & -0.00 & -0.00 to -0.00 & $<.001$ \\
\hline Age greater than median & & & & 1.29 & $0.23-2.34$ & .020 \\
\hline Female & & & & 0.58 & -0.64 to 1.79 & .354 \\
\hline
\end{tabular}

$B$, Estimated effect; $C I$, confidence interval. Bold signifies $P$ values below 5\%. Time is measured in weeks. The final model of the model selection process includes all terms up to a cubic time trend. Model 1 unadjusted model, model 2 adjusted for age and sex. *Intercept terms: For model 2, this is the value for young (age $<66$ years) man. 